\title{
THE ACID-BASE EQUILIBRIUM OF THE BLOOD IN ACUTE RHEUMATISM.
}

\author{
BY
}

\author{
LEONARD G. PARSONS, M.D., F.R.C.P., and S. H. EDGAR, Ph.D., M.Sc. \\ (From the Department of Diseases of Children of the University \\ of Birmingham.)
}

One of the earliest conceptions of the nature of acute rheumatism was based upon the humoral theory and assumed that the pain of the disease was due to the flow of rheum from the brain and its final localization in the affected parts. Later this explanation was displaced by a chemical one. Thus some fifty to sixty years ago Maclagan ${ }^{1}$ wrote as follows :-

One of the characteristics of acute rheumatism is the occurrence of profuse acid perspiration. The urine is hyperacid, and even the naturally alkaline saliva may have an acid reaction. This excessive acidity naturally led to the hypothesis that an acid condition of the blood had something to do with the production of the rheumatic symptoms. Dr. Prout made the definite suggestion that the materies morbi was lactic acid, and that the rheumatic symptoms resulted from the accumulation of this acid in blood.

The acid theory, which possessed the advantage of a rational explanation of the then usual treatment by alkalies, was very generally held for a time; but now that the infective origin of acute rheumatism is commonly accepted, the question whether the causal organism may be one that produces an acid toxin has been raised. It therefore occurred to us that an investigation of the acid-base balance of the blood in rheumatism should give some evidence for or against this suggestion.

\section{Theoretical Considerations.}

It is well known that although normally the $\mathrm{pH}$ of the blood is extremely constant, certain pathological conditions and some experimentally produced abnormal states, can alter its value either in the direction of an acidosis or an alkalosis. Usually, however, any change tending to occur is speedily regulated by alterations in the excretory systems, which neutralize the disturbing effect and keep the $\mathrm{pH}$ constant. This is not always so, and as soon as the regulating mechanism breaks down, or its capacity becomes exhausted, a permanent alteration of $\mathrm{pH}$ is produced.

Alkali is contained in the blood mainly in the form of bicarbonate bound to sodium and other bases. The ratio or this to the free carbon dioxide deter-

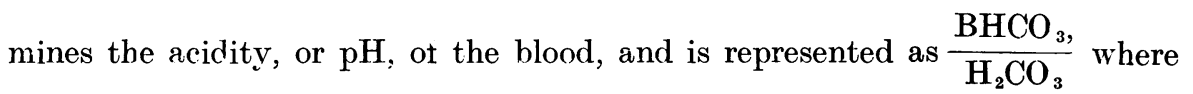
the $\mathrm{BHCO}_{3}$ is the total base bound to bicarbonate, and $\mathrm{H}_{2} \mathrm{CO}_{3}$ the free $\mathrm{CO}_{2}$. It will be seen that either an increase in $\mathrm{BHCO}_{3}$ or a decrease in $\mathrm{H}_{2} \mathrm{CO}_{3}$ will tend to have the same effect, a shift in the alkaline direction, or an 'alkalosis,' with a consequent increase of $\mathrm{pH}$; similarly a decreased $\mathrm{BHCO}_{3}$ or an increased $\mathrm{H}_{\tilde{\kappa}} \mathrm{CO}_{3}$ will tend to produce an acidosis, indicated by a lower $\mathrm{pH}$. 
That this change in $\mathrm{pH}$ is not generally obtained is due to the compensation described above. For example, an alkalosis due to decreased $\mathrm{H}_{2} \mathrm{CO}_{3}$ through increased breathing and consequent rapid removal of $\mathrm{CO}_{2}$ from the blood, will be compensated by increased excretion of the base in the urine which will become alkaline in reaction. This tends to restore the ratio $\frac{\mathrm{BHCO}_{3}}{\mathrm{H}_{2} \mathrm{CO}_{3}}$ to normal. The condition is found $\mathrm{i}$ i individuals breathing sir at high altitudes, where the oxygen tension is low. An acidosis may be produced by increased formation of non-volatile acids in the body, as in cliabetes ; or by their faulty excretion, as in nephritis. Violent muscular exertion, with formation of lactic acid, has a similar result. Compensation will be effected by increased respiration which, by rapid elimination of carbon clioxide, lowers the acidity towards normal, but should a point be reached where the regulating mechanism is unable to cope with the disturbing factor, as for example in a case of diabetes where the production of non-volatile acids is continuous, the $\mathrm{pH}$ will be altered, and an abnormal figure obtained. This is the condition of uncompensated acidosis.

For a knowledge of the acid-base balance or equilibrium of a given specimen of blood two estimations are necessary, the $\mathrm{pH}$ and the carbon dioxide content. The latter figure is not to be confused with the term 'alkeli reserve.' Carbon dioxide is present in the blood in two states, partly free, dissolved physically in the plasma, and partly combined with alkali in the form of bicarbonate. It is the combined $\mathrm{CO}_{2}$ which is referred to by the term ' alkali reserve,' while the figure obtained in estimating the acid-base equilibrium is that of the total $\mathrm{CO}_{2}$. The reason that so little distinction is made between the two values is that the free $\mathrm{CO}_{2}$, besides being only a small fraction $(5 \%)$ of the total is an extremely constant quantity. Hence variations in the total $\mathrm{CO}_{2}$ may be ascribed exclusively to the bicarbonate portion, or alkali reserve.

\section{Present Investigations.}

In this work the $\mathrm{pH}$ was determined electrometrically, using a quinhydrone electrode of the micro-form devised by Cullen and Biimann², and the carbon dioxide by Van Slyke's method. For illustrating the results obtained use has been made of Van Slyke's graph (see Fig. 1). The ordinates give the $\mathrm{CO}_{2}$, the abscissæ the pH. The heavy lines show the extreme limits for normal blood which Van Slyke has adopted from figures given by different workers. We have ourselves obtained a higher $\mathrm{pH}$ range than that given, probably due to the use of the quinhydrone electrode, which was not in use when Van Slyke's figures were obtained. It will also be seen that a narrower range of results has been found for the $\mathrm{CO}_{2}$ content. Our own ' normal limits' are given in broken lines on the same chart.

The nine areas which are formed represent the nine possible conditions of the blood. The three in the centre column are those most commonly met, being the three with normal $\mathrm{pH}$ : that is, compensated $\mathrm{CO}_{2}$ (or alkali) excess and deficit respectively, and the normal area.

From the acid-base figures alone it is, of course, impassible to say whether a high $\mathrm{CO}_{2}$ result is a compensated alkali or $\mathrm{CO}_{2}$ excess ; that is, whether excess 
FIG. I.

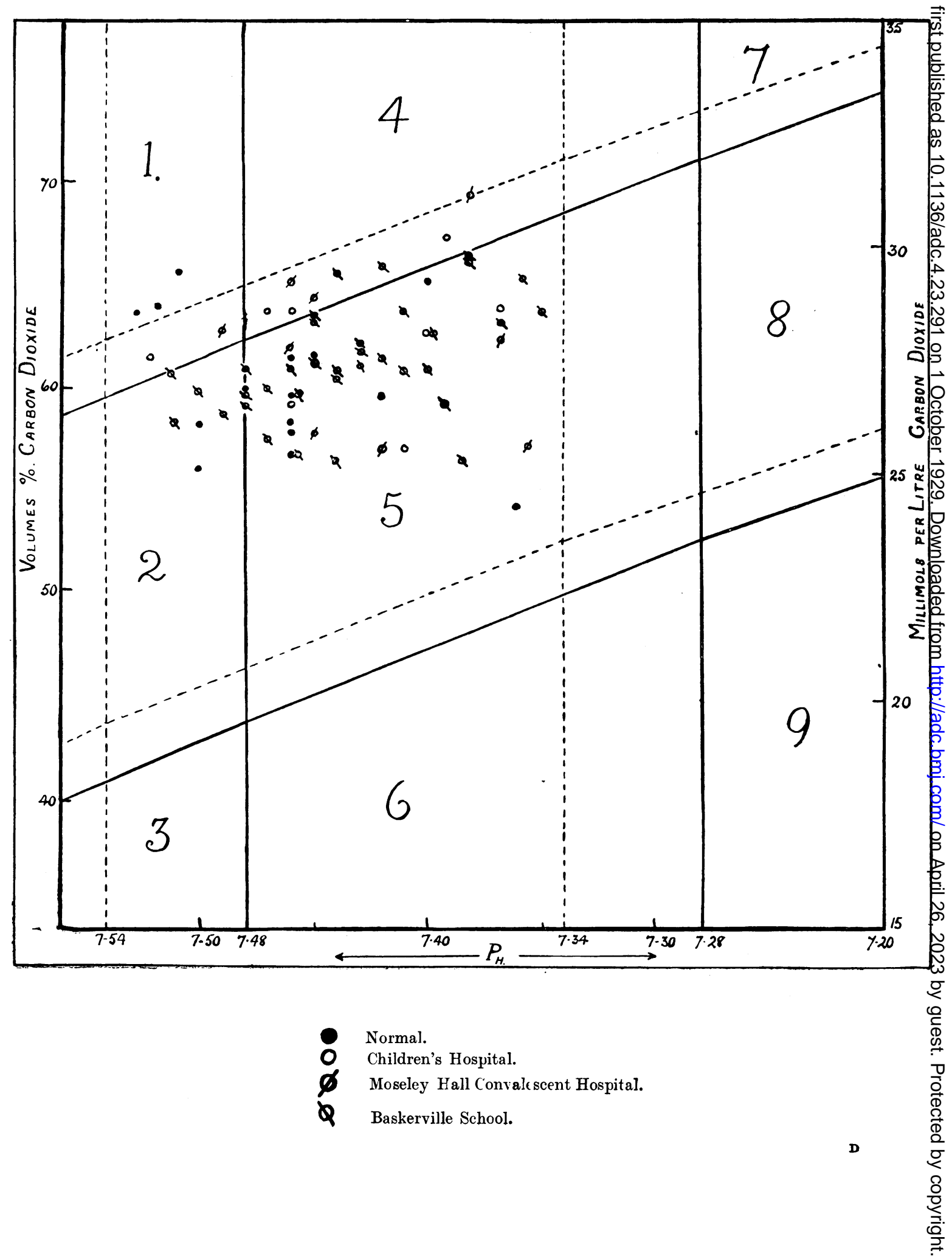


of alkali was the primary disturbance compensated by $\mathrm{CO}_{2}$ retention, or excess of $\mathrm{CO}_{2}$ compensated by alkali retention; the same is true for a compensated deficit. In either case clinical or further biochemical evidence may indicate the actual condition.

The total $\mathrm{CO}_{2}$ is given at the two sides of the chart as volumes per cent carbon dioxide and millimols per litre. The latter, which is obtained by dividing volumes per cent by $\mathbf{2} \cdot 2 \cdot 26$, is the nomenclature more common among American workers.

The areas on the graph are as follows :-
1. Uncompensated alkali excess.
6. Compensated alkali or $\mathrm{CO}_{2}$ deficit.
2 and 3. Uncompensated $\mathrm{CO}_{2}$ deficit.
4. Compensated alkali or $\mathrm{CO}_{2}$ excess.
5. Normal balance.
7 and 8 . Uncompensated $\mathrm{CO}_{2}$ excess.
9. Uncompensated alkali deficit.

\section{Results of Investications.}

The treatment of children suffering from acute rheumatism in the City of Birmingham has been so organised that the patient may obtain continuous institutional treatment for a period of one to two years or even longer. The scheme has been outlined by Thomson ${ }^{3}$ and briefly it aims at ensuring that the child shall have three different forms of treatment in three instituticns:(1) Treatment during the acute phase in the Children's Hospital : followed by (2) six to nine months in Moseley Hall Convalescent Hospital for Children, during the greater part of which time the child is kept in bed : after which (3) the child is transferred to Baskerville School, a residential school under the Education Authority. The average duration of time spent at this institution is about nine months.

For the purpose of this investigation the acid-base balance of the blood has been estimated in fifty-three cases drawn from all of the groups described above. By this means it has been possible to compare the results obtained from children in all stages of the discase, acute, convalescent and quiescent. For comparison with these the acid-base balance of the blood has been estimated in fifteen healthy elementary school children.

The results show that the normal and the rheumatic cases occupy the same area of the graph, there being no tendency for the pathological examples to group themselves in, or even to approach towards, any of the areas representing an abnormal condition.

Table 1 shows a summary of the results obtained.

TABLE I.

SUMMARY OF RESULTS IN RHECMATIC AND NORMAL CHILDREN.

\begin{tabular}{|c|c|c|c|c|c|c|}
\hline & & & & $\begin{array}{c}\text { No. } \\
\text { of C'ases }\end{array}$ & $\mathrm{pH}$. & $\begin{array}{c}\mathrm{CO}_{2} \\
\text { (vols. } \% \text { ) }\end{array}$ \\
\hline $\begin{array}{llll}\text { Hospital } & \ldots & \ldots & \ldots\end{array}$ & $\ldots$ & $\ldots$ & $\ldots$ & 7 & $7 \cdot 47$ & $62 \cdot 08$ \\
\hline Moseley Convalescent Hospital & $\ldots$ & $\ldots$ & $\ldots$ & 10 & $7 \cdot 42$ & $62 \cdot 03$ \\
\hline Baskerville School ... . . ... & $\ldots$ & $\ldots$ & $\ldots$ & 36 & $7 \cdot 43$ & $60 \cdot 87$ \\
\hline Normal $\quad \ldots \quad \ldots$ & $\ldots$ & $\ldots$ & $\ldots$ & 15 & $7 \cdot 46$ & $59 \cdot 34$ \\
\hline
\end{tabular}


Table 2 shows the details of the included cases.

TABLE 2.

DETAILS OF RESULTS IN RHEUMATIC AND NORMAL CHILDREN.

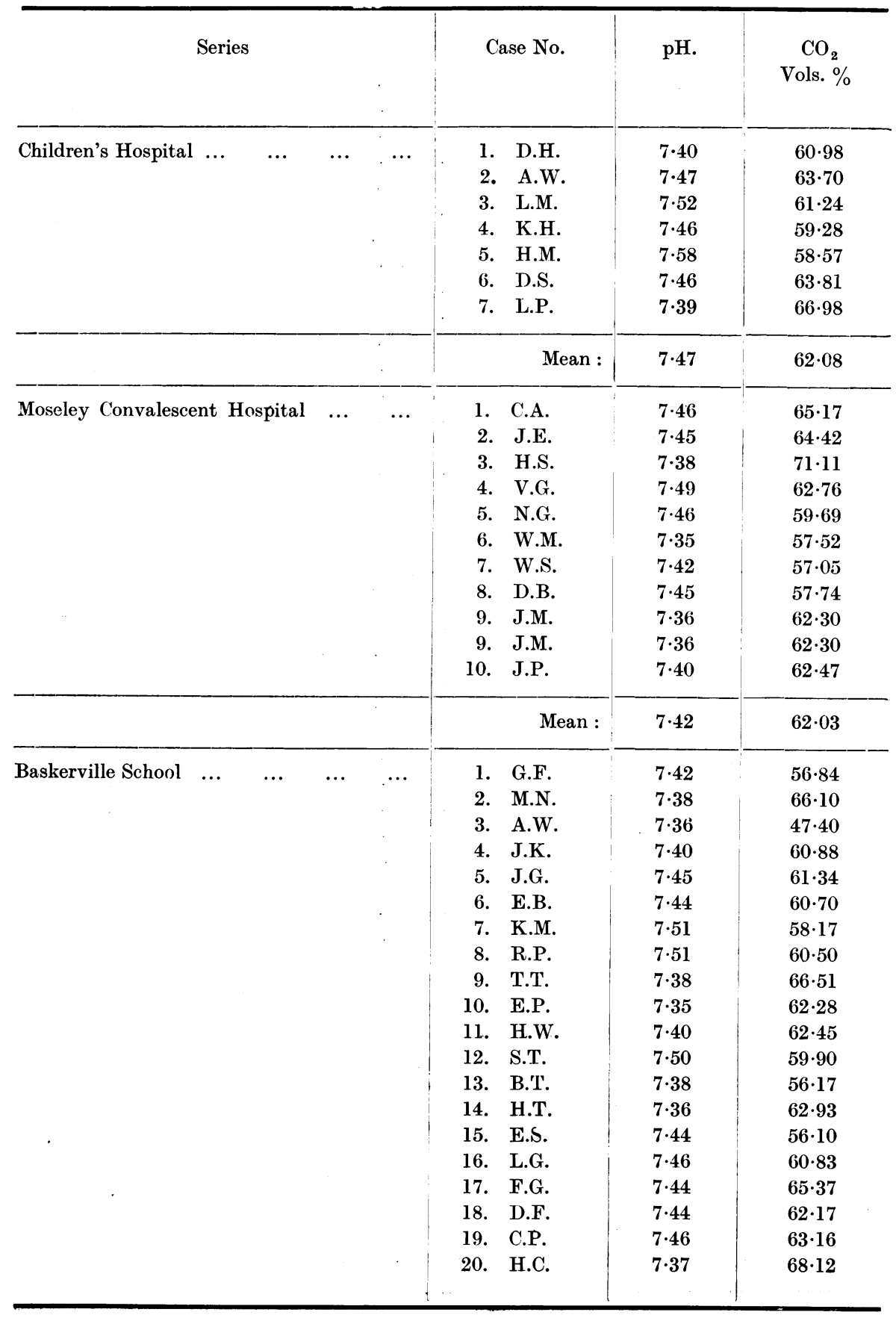


TABLE 2.-continued

Detall.S OF RESULTS IN RHEUMATIC AND NORMAL, CHILDREN.

\begin{tabular}{|c|c|c|c|c|c|}
\hline \multicolumn{3}{|l|}{ Series. } & Case No. & $\begin{array}{c}\mathrm{pH} . \\
7 \cdot 46\end{array}$ & $\begin{array}{c}\mathrm{CO}_{2} \\
\text { Vols. } \%\end{array}$ \\
\hline Baskerville School (contd.) ... & $\ldots$ & $\cdots$ & $\begin{array}{ll}21 . & \text { L.M. } \\
22 . & \text { T.P. } \\
23 . & \text { C.H. } \\
24 . & \text { O.P. } \\
25 . & \text { H.L. } \\
26 . & \text { K.C. } \\
27 . & \text { D.W. } \\
28 . & \text { F.V. } \\
29 . & \text { D.S. } \\
\text { 30. } & \text { E.J. } \\
\text { 31. } & \text { R.B. } \\
\text { 32. } & \text { A.P. } \\
\text { 33. } & \text { S.R. } \\
\text { 34. } & \text { D.B. } \\
\text { 35. } & \text { M.G. } \\
\text { 36. } & \text { R.V. }\end{array}$ & $\begin{array}{l}7 \cdot 46 \\
7 \cdot 48 \\
7 \cdot 48 \\
7 \cdot 49 \\
7 \cdot 43 \\
7 \cdot 47 \\
7 \cdot 47 \\
7 \cdot 42 \\
7 \cdot 42 \\
7 \cdot 43 \\
7 \cdot 41 \\
7 \cdot 48 \\
7 \cdot 36 \\
7 \cdot 45 \\
7 \cdot 41 \\
7 \cdot 44\end{array}$ & $\begin{array}{l}56 \cdot 31 \\
60 \cdot 07 \\
59 \cdot 30 \\
58 \cdot 25 \\
61 \cdot 17 \\
59 \cdot 92 \\
57 \cdot 40 \\
61 \cdot 52 \\
65 \cdot 80 \\
61 \cdot 18 \\
68 \cdot 83 \\
60: 83 \\
64 \cdot 60 \\
57 \cdot 30 \\
60 \cdot 64 \\
60 \cdot 25\end{array}$ \\
\hline & & & Mean : & $7 \cdot 43$ & $60 \cdot 87$ \\
\hline $\begin{array}{lll}\cdots & \cdots & \cdots\end{array}$ & $\ldots$ & $\ldots$ & $\begin{aligned} \text { 1. } & \text { G.C. } \\
2 . & \text { N.H. } \\
\text { 3. } & \text { H.O. } \\
\text { 4. } & \text { B.W. } \\
\text { 5. } & \text { W.J. } \\
6 . & \text { G.W. } \\
7 . & \text { R. } \\
\text { 8. } & \text { V.G. } \\
9 . & \text { A.F. } \\
\text { 10. } & \text { D.F. } \\
\text { 11. } & \text { P.E. } \\
\text { 12. } & \text { S.G. } \\
\text { 13. } & \text { R.T. } \\
\text { 14. } & \text { J.W. } \\
\text { 15. } & \text { J.M. }\end{aligned}$ & $\begin{array}{l}7 \cdot 50 \\
7 \cdot 52 \\
7 \cdot 46 \\
7 \cdot 46 \\
7 \cdot 40 \\
7 \cdot 48 \\
7 \cdot 46 \\
7 \cdot 45 \\
7 \cdot 46 \\
7 \cdot 46 \\
7 \cdot 51 \\
7 \cdot 50 \\
7 \cdot 42 \\
7 \cdot 36 \\
7 \cdot 44\end{array}$ & $\begin{array}{l}58 \cdot 06 \\
64 \cdot 07 \\
61 \cdot 35 \\
58 \cdot 15 \\
65 \cdot 10 \\
59 \cdot 91 \\
57 \cdot 85 \\
61 \cdot 58 \\
56 \cdot 70 \\
59 \cdot 70 \\
65 \cdot 50 \\
55 \cdot 85 \\
59 \cdot 55 \\
54 \cdot 21 \\
53 \cdot 54\end{array}$ \\
\hline & & & Mean : & $7 \cdot 46$ & $59 \cdot 34$ \\
\hline
\end{tabular}

Jiscussion.

The only definite statement in the literature bearing on the acid-base equilibrium in acute rheumatism that we can trace is by Benzançon and Weill', who in a communication published last year state that the blood $\mathrm{pH}$ and the alkali reserve are normal in rheumatic patients. This paper does not contain details given of the number of cases examined, the state of the disease at the time of the examination, nor the methods used. Nevertheless we find ourselves in complete agreement with their statement. 
Since our enquiry was started a book has been published on "Recent Advances in Pædiatrics " in which the authors (Pearson and Wyllie ${ }^{5}$ ) return to the idea of a chemical basis of the disease. They consider that the picture of a child with subacute attacks of rheumatism is similar to that of the fatigued man in whom the symptoms are due to excess of lactic acid in the muscles and other tissues and that " clinical evidence is overwhelming in support of the " " acid ' basis of the disease." They regard the pains of rheumatism as caused primarily by excess of acid in the body, infection only accounting for 'some of the later effects.' Further, they say that there is a constitutional predisposition to acute rheumatism, and that the type of child which is likely to develop the disease can be recognized, and to this type they have given the title of the acid or hypercalcic child. In such children calcium and phosphorus are present in the tissues in excess, and whereas normally phosphorus is combined with calcium 'it is possible that in rheumatism phosphorus is present in excess of 'calcium.' Finally, we are invited to believe that chorea is due to an excess of phosphate which collects in the area of the brain where the circulation is most likely to stagnate, i.e., in the cerebellum.

These authors have attempted to forestall possible criticism by saying,

It is now recognized that it is an obvious fallacy to regard the blood as a criterion of the state of the tissues. The blood is merely a supply and drainage system which carries materials to be utilised or eliminated. It cannot be held to represent the actual conditions of the tissues which it serves. The blood is apparently normal, yet the tissues are acid.

Whilst it could be argued from first principles that the investigation of variations in the contents of a supply and drainage system might throw light on the changes which are taking place within the structures it serves, we prefer to answer this contention by the following quotation from a recent paper by Marriott and Hartmann ${ }^{5}$.

The actual composition of the tissue cells cannot be determined during life but it has been demonstrated, chiefly by the work of Van Slyke, that one can predict changes in the red blood cells from changes in the plasma by application of the Donnan principle of ionic and osmotic equilibrium existing when a membrance is not permeable to all the solutes present. It seems almost certain that a similar equilibrium exists between the Jymph and the tissue cells, and it has already been shown that this equilibrium exists between the plasma and the lymph. Therefore by a study of the blood plasma is obtained a picture of the changes which are occurring at the same time within the cells.

We admit the correctness of Pearson and Wyllie's statement that a marked or prolonged change in reaction does not occur except as a fatal event, but would point out that there is such a thing as ' compensated acidosis,' and that in fact this actually occurs in the very condition of the excessive exercise or fatigue which they have invoked as comparable with the symptoms of subacute rheumatism. With regard to calcium they argue that an estimation of blood calcium is not an index of the calcium ions either in the circulatory or body fluids. Whilst it is true that the estimation of blood calcium does not give a direct indication of the calcium ions present, yet such an estimationisextremely useful for comparative purposes, since providing the $\mathrm{pH}$ of the blood remains constant, the blood calcium does give an indirect indication of ionic calcium. 
In this paper we have only dealt with the acid-base equilibrium, but one of us (S.H.E.) has investigated among other factors variations in blood calcium in rheumatism, and the results obtained will shortly be published. The results obtained show that there is no experimental evidence in favour of the view that there is an excess of acid in the tissues of the rheumatic child. We have felt the importance of examining the point of view of these writers in some detail because already their statements are being accepted by examination candidates, many of whom have adopted both the hyper- and hypo-calcic child with a considerable, but in our view unmerited and misplaced, affection.

\section{Conclusions.}

1. The acid-base equilibrium of children suffering from acute rheumatism, whether in the acute, convalescent or quiescent stages of the disease, is normal.

2 . There is no evidence in favour of the view that the symptoms of rheumatism are due to an excess of acid in the tissues, or that the rheumatic child is an ' acid' child.

The expenses of these investigations were defrayed by the Medical Research Council to whom we would tender our thanks.

\section{REFERENCES.}

1. Maclagan, T. J., Rheumatism, Lond., 2nd Ed., 1896, 30.

2. Cullen, G. E., and Biilmann, E., J. Biolog. Chem., Baltimore, 1925, LXIV, 727.

3. Thomson, A. P., Proc. Conference Rheumatic Dis., Bath, 1928, 32.

4. Benzançon, F., \& Weill, M., Loc. cit., 167.

5. Pearson, W. J., \& Wyllie, W. G., Recent Advances in Dis. Children, Lond., 1928, 30 et seq.

6. Marriott, W. M., \& Hartmann, A. F., J. Amer. Med. Ass., Chic., 1928, XCI, 1675. 